\title{
Maternal pre-pregnancy body mass index and newborn telomere length
}

\author{
Dries S. Martens ${ }^{1}$, Michelle Plusquin ${ }^{1,2}$, Wilfried Gyselaers ${ }^{3}$, Immaculata De Vivo ${ }^{4,5}$ and Tim S. Nawrot ${ }^{1,6^{*}}$
}

\begin{abstract}
Background: Newborn telomere length sets telomere length for later life. At birth, telomere length is highly variable among newborns and the environmental factors during in utero life for this observation remain largely unidentified. Obesity during pregnancy might reflect an adverse nutritional status affecting pregnancy and offspring outcomes, but the association of maternal pre-pregnancy body mass index (BMI) with newborn telomere length, as a mechanism of maternal obesity, on the next generation has not been addressed.

Methods: Average relative telomere lengths were measured in cord blood $(n=743)$ and placental tissue $(n=702)$ samples using a quantitative real-time PCR method from newborns from the ENVIRONAGE birth cohort in Belgium. By using univariate and multivariable adjusted linear regression models we addressed the associations between pre-pregnancy BMI and cord blood and placental telomere lengths.

Results: Maternal age was 29.1 years (range, 17-44) and mean (SD) pre-pregnancy BMI was 24.1 (4.1) kg/m². Decline in newborn telomere length occurred in parallel with higher maternal pre-pregnancy BMI. Independent of maternal and paternal age at birth, maternal education, gestational age, newborn gender, ethnicity, birthweight, maternal smoking status, parity, cesarean section, and pregnancy complications, each $\mathrm{kg} / \mathrm{m}^{2}$ increase in pre-pregnancy BMl was associated with a $-0.50 \%(95 \% \mathrm{Cl},-0.83$ to $-0.17 \% ; P=0.003)$ shorter cord blood telomere length and a $-0.66 \%$ (95\% Cl, -1.06 to $-0.25 \% ; P=0.002$ ) shorter placental telomere length.

Conclusions: Maternal pre-pregnancy BMI is associated with shorter newborn telomere lengths as reflected by cord blood and placental telomeres. These findings support the benefits of a pre-pregnancy healthy weight for promoting molecular longevity from early life onwards.
\end{abstract}

Keywords: Telomeres, Newborns, Pre-pregnancy body-mass index, in utero life

\section{Background}

The prevalence of overweight and obesity is rising worldwide, including in women of reproductive age. Maternal overweight and obesity are well-known risk factors for adverse pregnancy outcomes and maternal body mass index (BMI) is also associated with maternal blood glucose levels during pregnancy [1]. Higher risks for pregnancy complications, such as preeclampsia [2], gestational diabetes [3], hypertensive disorders [4], and cesarean delivery [5], have been associated with maternal obesity. Telomeres are nucleoprotein structures containing TTAGGG repeats at the end of the chromosomes.

\footnotetext{
* Correspondence: tim.nawrot@uhasselt.be

${ }^{1}$ Centre for Environmental Sciences, Hasselt University, Hasselt 3500, Belgium ${ }^{6}$ Department of Public Health \& Primary Care, Leuven University, Leuven 3000, Belgium

Full list of author information is available at the end of the article
}

They are important in maintaining genomic stability and protect chromosomes from end-to-end fusion and degradation [6]. Telomere length is considered a biomarker of biological ageing and has been associated with age-related diseases such as cardiovascular disease $[7,8]$, type 2 diabetes [9], atherosclerosis [10, 11], and increased mortality [12-14]. Telomere length variability and attrition rate has been explained by heritability and by different environmental determinants [15-19]. Even at birth newborn telomere lengths are highly variable $[20,21]$ and the rate of telomere shortening is higher during the first 4 years of life compared to later life [22].

Environmental factors during in utero life that potentially explain the observed telomere length variability in newborns remain largely unidentified since large population-based studies of telomere lengths in relation 
with environmental factors and age-related diseases have traditionally recruited middle-aged subjects [23, 24]. Nevertheless, interest of in utero factors (physiological, social, environmental, demographical, and clinical exposures during pregnancy) in relation to newborn telomere biology is rising [24]. Indeed, recent studies have shown that newborn telomere length is influenced by intrauterine effects such as exposure to maternal stress [25, 26], maternal smoking [27], maternal education [28], maternal folate concentrations [29], pre-eclampsia, and intrauterine growth restriction [30, 31], as well as by diabetes during pregnancy [32]. These findings reflect the importance of in utero and early life exposures in the determination of initial telomere lengths at birth and show that these exposures may have an impact on ageing, disease susceptibility, and molecular longevity later in life. Telomere length in adulthood is associated with BMI [33], but the influence of pre-pregnancy weight through the intrauterine environment on telomere length has not been addressed. Maternal undernutrition during in utero development of the fetus has been associated with coronary heart disorders [34], increased BMI [35, 36], and hypertension [35, 37]. During pregnancy, maternal obesity might influence the in utero environment, which can lead to altered fetal development, physiology, and metabolism, potentially underlying the origin of later life diseases and possibly having an impact on later life health [38]. Maternal obesity is associated with abnormal fetal growth [39], increased risks of birth defects $[40,41]$, fetal death, still birth, and infant death [42]. Later life health states, such as childhood obesity [43], childhood asthma [44], and cardiovascular diseases $[45,46]$, are associated with maternal obesity. These observations are consistent with the developmental origin of disease hypothesis [47]. We hypothesized that maternal overweight and obesity during pregnancy might be important in setting telomere length at birth and may therefore contribute to the developmental programming of the child. The aim of the present study was to evaluate the possible effects of maternal obesity in a representative cohort of newborns on telomere length measured in fetal cord blood DNA and placental DNA.

\section{Methods}

\section{Study population and data collection}

This study included 768 mother-newborn pairs (singletons) selected from the ongoing ENVIRONAGE (ENVIRonmental influence ON AGEing in early life) birth cohort in the province of Limburg in Belgium. The study protocol was approved by the Ethical Committee of Hasselt University and East-Limburg Hospital in Genk (Belgium) and has been carried out according to the declaration of Helsinki. Written informed consent was obtained from all participating mothers. In total, 768 mothers with a singleton pregnancy and all with a pre- pregnancy BMI below $40 \mathrm{~kg} / \mathrm{m}^{2}$ were recruited from February 1, 2010, to February 1, 2015, between Friday 1200 hours and Monday 0700 hours. The mother's ability to fill out questionnaires in Dutch was a criterion for selection. The overall participation rate was $61 \%$. Because DNA was missing or of bad quality for cord blood DNA $(n=14)$ or for placental DNA $(n=57)$ or because telomere length measurements were too variable between triplicate measurements for cord blood telomere $(n=10)$ or placental telomere $(n=8)$, and because of missing data on maternal weight gain during pregnancy $(n=1)$, the final sample consisted of 743 mother-newborn pairs to study associations with cord blood telomere lengths and 702 mother-newborn pairs to study associations with placental telomeres (Additional file 1: Figure S1).

Data on maternal pre-pregnancy weight, weight before delivery, and height were collected from the medical records at the hospital. Maternal height and weight were measured without shoes, wearing light clothes to the nearest centimeter and weight to the nearest $0.1 \mathrm{~kg}$ at the first antenatal visit of each pregnancy (weeks 7-9 of gestation). BMI was defined as weight in kilograms divided by the square of height in meters. Gestational age was estimated based on ultrasound data. Pre-pregnancy BMI was categorized into three categories; normal was defined as BMI below $25 \mathrm{~kg} / \mathrm{m}^{2}$, overweight when BMI was greater than or equal to $25 \mathrm{~kg} / \mathrm{m}^{2}$ and below $30 \mathrm{~kg} / \mathrm{m}^{2}$, and obese was defined when BMI was greater than or equal to $30 \mathrm{~kg} / \mathrm{m}^{2}$. Furthermore, the women were weighed on admission to the delivery ward. Maternal pregnancy weight gain (weight before delivery minus pre-pregnancy weight) was categorized according to the Institute of Medicine guidelines - we defined insufficient and excessive gestational weight gain in relation to maternal pre-pregnancy BMI (for underweight: total weight gain $<13$ and $>18 \mathrm{~kg}$; normal weight: total weight gain $<11.5$ and $>16.0 \mathrm{~kg}$; for overweight: total weight gain $<7.0$ and $>11.5 \mathrm{~kg}$; for obesity: total weight gain $<5.0$ and $>9.0 \mathrm{~kg}$, respectively) [48].

Study questionnaires were completed in the post-delivery ward to provide detailed information on maternal age, paternal age, maternal education (as a measure for socioeconomic status), smoking status, parity, ethnicity, and pregnancy complications. Maternal smoking status was assessed as former smokers who had quit smoking before pregnancy and smokers who continued smoking during pregnancy. Maternal education was coded low when mothers only went to primary school and did not obtain a diploma, middle as they obtained a high school diploma and high when they obtained a college or university degree.

Newborn's ethnicity was classified as European-Caucasian when two or more grandparents were European or non-European when at least three grandparents were of non-European origin. Information on pregnancy complications were collected from the medical records for 
each mother. Pregnancy complications was coded as absent if mothers did not experience any pregnancy complications or as present if mothers experienced one or more pregnancy complications. Included pregnancy complications were gestational diabetes, hypertension, infection diseases, pre-eclampsia, vaginal bleeding, and hyper- or hypothyroidism. Perinatal parameters were obtained after birth such as birth date, newborn gender, birth weight, and Apgar score. The ENVIRONAGE birth cohort is generalizable to the gestational segment of the population at large as it did not differ from all births in Flanders as to maternal age, education, parity, newborn gender, ethnicity, and birth weight (Additional file 1: Table S1) [49].

\section{Cord blood and placental tissue collection}

Umbilical cord blood was drawn immediately after delivery in BD Vacutainer ${ }^{\odot}$ plastic whole blood tubes with spray-coated K2EDTA (BD, Franklin Lakes, NJ, USA). Samples were centrifuged at $3200 \mathrm{rpm}$ for $15 \mathrm{~min}$ and blood tubes were stored at $-80{ }^{\circ} \mathrm{C}$. Buffy coat was removed upon DNA extraction. Placentas were collected and stored at $-20{ }^{\circ} \mathrm{C}$ within 10 minutes after delivery. Placental biopsies were taken at the fetal site and stored at $-80{ }^{\circ} \mathrm{C}$ upon DNA extraction as described previously [50]. For each placenta, four different biopsies were taken at four standardized sites across the middle region of the placenta, at $4 \mathrm{~cm}$ approximately from the umbilical cord. First, we determined within-placental average relative telomere length variation in 14 different placentas based on the four different biopsies. This average within placental variation was $11.7 \%$. Because of the low variation in telomere length within the placenta for different biopsies we used only one biopsy $\left(1-2 \mathrm{~cm}^{3}\right)$ taken to the right of the main artery for placental telomere length assessment.

\section{Average relative telomere length measurement}

DNA was extracted from cord blood buffy coat and placental tissue using the QIAamp DNA Mini Kit (Qiagen, Inc., Venlo, The Netherlands). DNA quantity and purity was assessed by a Nanodrop 1000 spectrophotometer (Isogen, Life Science, Belgium). DNA integrity was assessed by agarose gel-electrophoresis. Average relative telomere length was measured by a modified quantitative real-time PCR (qPCR) protocol as described previously [51]. To ensure a uniform DNA input of $5 \mathrm{ng}$ for each qPCR reaction, samples were diluted and checked using the Quant-i $\mathrm{T}^{\mathrm{rm}}$ PicoGreen ${ }^{\circledast}$ dsDNA Assay Kit (Life Technologies, Europe). Telomere and single copy-gene reaction mixture and PCR cycles used are given in Additional file 1: Text S1. All measurements were performed in triplicate on a 7900HT Fast Real-Time PCR System (Applied Biosystems) in a 384-well format. On each run, a 6-point serial dilution of pooled buffy coat or pooled placental DNA was run to assess PCR efficiency as well as eight inter-run calibrators to account for inter-run variability. Relative average telomere lengths were calculated using qBase software (Biogazelle, Zwijnaarde, Belgium) and were expressed as the ratio of telomere copy number to singlecopy gene number $(\mathrm{T} / \mathrm{S})$ relative to the average $\mathrm{T} / \mathrm{S}$ ratio of the entire sample set. Before our study, we performed an interlaboratory comparison of our telomere assay with a US reference lab to standardize the protocol. We achieved coefficients of variation $(\mathrm{CV})$ within triplicates of the telomere runs, single-copy gene runs, and $\mathrm{T} / \mathrm{S}$ ratios of $0.68 \%$, $0.41 \%$, and $6.4 \%$, respectively, for cord blood telomeres. For placental telomeres, we achieved CVs of $0.70 \%$, $0.45 \%$, and $6.9 \%$, for telomere runs, single-copy gene runs, and $\mathrm{T} / \mathrm{S}$ ratios, respectively.

\section{Statistical analysis}

All statistical analyses were performed using the SAS 9.3 statistical software (SAS Institute Inc., Cary, NC, USA). Continuous variables were tested for normality. Average relative cord blood and placental telomere lengths showed skewed distribution and were log10 transformed to improve normal distribution. To study potential confounding structure in our dataset, we assessed the distributions of continuous variables (ANOVA) and proportions of categorical variables ( $\chi^{2}$ test) across different classes of maternal pre-pregnancy BMI (normal, overweight, and obese). Pearson correlation (unadjusted analysis) and multiple linear regressions were applied to address the association between maternal pre-pregnancy BMI and cord blood or placental telomere lengths. In a first model, we adjusted for maternal and paternal age, maternal education, newborn gender, gestational age and birth weight. In a second model, we additionally adjusted for parity, maternal smoking status, newborn ethnicity, cesarean section, and pregnancy complications. Finally, we introduced maternal net weight gain during pregnancy to our models as a continuous variable as well as a categorical variable coded as sufficient and insufficient weight gain using the definition of Institute of Medicine guidelines (see Study population and data collection). In order to test whether the association of gestational weight gain on newborn telomere length is influenced by maternal pre-pregnancy BMI, we tested the interaction between weight gain and pre-pregnancy BMI. We ran different sensitivity analyses in which we separately excluded mothers from nonEuropean origin, those with pre-pregnancy BMI less than 18.5, those who underwent cesarean section, or those who experienced complications during pregnancy.

\section{Results}

\section{Study population characteristics}

Demographic characteristics and perinatal factors of 743 mother-newborn pairs are reported in Table 1. Briefly, mean maternal age was 29.1 years (range, 17-44) and 
Table 1 Mother-newborn characteristics according to maternal pre-pregnancy BMI

\begin{tabular}{|c|c|c|c|c|}
\hline Characteristic & $\begin{array}{l}\text { Normal weight } \\
n=488\end{array}$ & $\begin{array}{l}\text { Overweight } \\
n=175\end{array}$ & $\begin{array}{l}\text { Obese } \\
n=80\end{array}$ & $P$ for trend \\
\hline \multicolumn{5}{|l|}{ Newborn } \\
\hline \multicolumn{5}{|l|}{ Gender } \\
\hline Girls, n & $251(51.4 \%)$ & $84(48.0 \%)$ & $41(51.3 \%)$ & 0.73 \\
\hline European-Caucasian, n & $441(90.4 \%)$ & 151 (86.3 \%) & $66(82.5 \%)$ & 0.07 \\
\hline Gestational age, weeks & $39.1(1.5)$ & $39.3(1.4)$ & $39.3(1.7)$ & 0.27 \\
\hline Birth weight, g & 3351 (468) & $3490(453)$ & $3502(524)$ & 0.0005 \\
\hline \multicolumn{5}{|l|}{ Maternal } \\
\hline Age, years & $29.2(4.5)$ & $29.3(4.6)$ & $28.4(4.5)$ & 0.34 \\
\hline \multicolumn{5}{|l|}{ Education } \\
\hline Low, n & $54(11.1 \%)$ & $18(10.3 \%)$ & $11(13.8 \%)$ & 0.25 \\
\hline Middle, $n$ & $170(34.8 \%)$ & $70(40.0 \%)$ & $36(45.0 \%)$ & \\
\hline High, n & $264(54.1 \%)$ & 87 (49.7 \%) & $33(41.3 \%)$ & \\
\hline \multicolumn{5}{|l|}{ Smoking status } \\
\hline Never smoker, $\mathrm{n}$ & $305(62.5 \%)$ & 109 (62.3 \%) & $51(63.8 \%)$ & 0.80 \\
\hline Stopped smoker, n & $118(24.2 \%)$ & $39(22.3 \%)$ & $21(26.3 \%)$ & \\
\hline Continued smoker, n & $65(13.3 \%)$ & $27(15.4 \%)$ & $8(10.0 \%)$ & \\
\hline Cesarean section, $\mathrm{n}$ & $13(2.7 \%)$ & $13(7.4 \%)$ & $7(8.8 \%)$ & 0.005 \\
\hline Pregnancy complication, $\mathrm{n}$ & $38(7.8 \%)$ & $23(13.1 \%)$ & $17(21.3 \%)$ & 0.006 \\
\hline \multicolumn{5}{|l|}{ Parity } \\
\hline $1, \mathrm{n}$ & $285(58.4 \%)$ & 86 (49.1%) & $46(57.5 \%)$ & 0.12 \\
\hline $2, n$ & $158(32.4 \%)$ & $63(36.0 \%)$ & $28(35.0 \%)$ & \\
\hline$\geq 3, n$ & $45(9.2 \%)$ & $26(14.9 \%)$ & $6(7.5 \%)$ & \\
\hline Pregnancy weight gain, kg & $14.9(5.2)$ & $14.1(6.5)$ & $11.4(6.1)$ & $<0.0001$ \\
\hline \multicolumn{5}{|l|}{ Paternal } \\
\hline Age, years & $31.7(4.9)$ & $31.7(4.7)$ & $31.1(5.7)$ & 0.59 \\
\hline
\end{tabular}

Classification of pre-pregnancy BMl classes: Normal when BMl $<25 \mathrm{~kg} / \mathrm{m}^{2}$, overweight when $25 \leq \mathrm{BMl}<30 \mathrm{~kg} / \mathrm{m}^{2}$, and obese when $\mathrm{BMI}>30 \mathrm{~kg} / \mathrm{m}^{2}$

Values are presented as means (SD) or $\mathrm{n}(\%)$

mean (SD) pre-pregnancy BMI was $24.1(4.1) \mathrm{kg} / \mathrm{m}^{2}$. Of the 743 mothers, 175 (23\%) were overweight and 80 (11 \%) were obese. Most women (63\%, $n=465)$ never smoked cigarettes and 178 women (24\%) stopped smoking before pregnancy, whereas 100 mothers (13\%) reported to have smoked during pregnancy (on average 8.6 cigarettes per day). The newborns, among them 376 girls (51\%), had a mean gestational age of 39.2 weeks (range, 30-42) and comprised 417 (56\%) primiparous and 249 (34\%) secundiparous newborns. About $89 \%(n=658)$ of the newborns were Europeans of Caucasian ethnicity. The mean (SD) birth weight of the newborns was 3400 (475) g. Five minutes after delivery, more than $90 \%$ of the newborns had an Apgar score of 9 or 10. Higher maternal pre-pregnancy BMI was associated with more cesarean sections ( $P$ for trend $=0.005)$, pregnancy complications $(P$ for trend $=0.006)$, and higher newborn birth weight $(P$ for trend $=0.0005)$. Obese mothers had gained less weight during pregnancy compared to normal weight and overweight mothers $(P$ for trend $<0.0001)$. The percentage of newborns from non-European origin was somewhat higher in the highest versus lowest BMI class (17\% vs. $10 \%)$.

\section{Predictors of newborn telomere length}

The relative telomere length ranged from 0.51 to 1.75 in cord blood and 0.52 to 1.89 in placental tissue. The cord placental telomere length correlation was $0.44(P<0.0001)$ (Additional file 1: Figure S2). Compared with newborn boys, newborn girls had $6.83 \%$ (95 \% CI, 4.27$9.30 \% ; P<0.0001)$ longer telomere length in cord blood and $5.24 \%$ (95 \% CI, 2.05-8.32\%; $P=0.002$ ) longer in placental tissue. Low maternal education was associated with shorter cord blood telomeres (-6.04\%; $95 \% \mathrm{CI},-10.18$ to $-1.71 \% ; P=0.007)$ when comparing to the highest maternal education level. Cord blood and 
placental telomere length increased with $0.27 \%(95 \%$ CI, -0.01 to $0.54 \% ; P=0.06)$ and $0.25 \%(95 \% \mathrm{CI},-0.08$ to $0.59 \% ; P=0.14$ ), respectively, for each year increase in paternal age. No significant associations were found with cord blood or placental telomeres and maternal age, maternal weight gain during pregnancy, gestational age, maternal smoking status, newborn ethnicity, pregnancy complications, or delivery modus.

\section{Association between pre-pregnancy BMI and newborn telomere length}

Compared to mothers with a normal weight, cord blood and placental telomere length were lower in overweight and obese women (Table 2). In continuous analysis, both before (Fig. 1) and after mutual adjustment for different sets of covariates and potential confounders, both cord blood and placental telomere length (Table 3) were consistently lower with higher pre-pregnancy BMI. For each unit $\left(1 \mathrm{~kg} / \mathrm{m}^{2}\right)$ increment in maternal pre-pregnancy BMI, cord blood telomere length was $0.50 \%$ shorter (95\% CI, -0.83 to $-0.17 \% ; P=0.003$ ) and placental telomere length was $0.66 \%$ shorter $(95 \% \mathrm{CI},-1.06$ to $-0.25 \%$; $P=0.002)$. Mothers gained weight during pregnancy on the average $(14.3 \pm 5.6 \mathrm{~kg})$ but further cumulative adjustment for maternal weight gain did not influence our results (Table 4). We did not observe a weight gain during pregnancy by pre-pregnancy BMI interaction with newborn cord $(P=0.85)$ or placental $(P=0.22)$ telomere length.
Categorical analysis showed no association of insufficient and sufficient weight gain during pregnancy on newborn telomere length (Table 4). Sensitivity analyses with exclusion of newborns from non-European origin, mothers with pre-pregnancy BMI less than 18.5, mothers that underwent cesarean sections, or experienced pregnancy complications did not materially alter our results (Table 5).

\section{Discussion}

Persons of the same age vary greatly with regards to telomere length and this variation is present from early life. The key finding of our paper is that pre-pregnancy BMI is associated with shorter newborn cord blood and placental telomeres. These associations remained unchanged after adjustments for paternal and maternal age at birth, maternal education, and newborn gender, birth weight, and gestational age. Our findings shed light on the pre-pregnancy effects of maternal BMI on the next generation. Indeed, our data showed that, for each BMI unit increase, average relative cord blood and placental telomeres were $0.50 \%$ and $0.66 \%$ shorter, respectively. The telomere loss in newborns of obese mothers may increase the risk for chronic diseases in adulthood. As we used a real-time PCR method we are not able to provide absolute values of telomere lengths to estimate the effects of our decline based on absolute values as measured, for instance, using terminal restriction fragments. Nevertheless, an estimation can be based on available

Table 2 Categorized pre-pregnancy maternal BMI and newborn telomere length

\begin{tabular}{|c|c|c|c|c|}
\hline & \multicolumn{2}{|l|}{ Cord blood $(n=743)$} & \multicolumn{2}{|l|}{ Placenta $(n=702)$} \\
\hline & Percentage change (95 \% Cl) & $P$ value & Percentage change (95 \% Cl) & $P$ value \\
\hline \multicolumn{5}{|l|}{ Unadjusted } \\
\hline$<25 \mathrm{~kg} / \mathrm{m}^{2}$ a & Ref & & Ref & \\
\hline Overweight $^{\mathrm{b}}$ & $-3.0(-6.1$ to 0.3$)$ & 0.07 & $-4.2(-7.9$ to -0.3$)$ & 0.03 \\
\hline Obese ${ }^{c}$ & $-5.7(-9.8$ to -1.3$)$ & 0.01 & $-3.7(-8.8$ to 1.6$)$ & 0.17 \\
\hline Overweight + Obese & $-3.8(-6.5$ to -1.0$)$ & 0.008 & $-4.1(-7.3$ to -0.7$)$ & 0.02 \\
\hline \multicolumn{5}{|l|}{ Model A } \\
\hline$<25 \mathrm{~kg} / \mathrm{m}^{2}$ & Ref & & Ref & \\
\hline Overweight $^{\mathrm{b}}$ & $-2.5(-5.6$ to 0.8$)$ & 0.13 & $-4.2(-7.8$ to -0.3$)$ & 0.04 \\
\hline Obese $^{c}$ & $-5.2(-9.3$ to -0.9$)$ & 0.02 & $-3.6(-8.7$ to 1.8$)$ & 0.19 \\
\hline Overweight + Obese & $-3.3(-6.0$ to -0.5$)$ & 0.02 & $-4.0(-7.3$ to -0.6$)$ & 0.02 \\
\hline \multicolumn{5}{|l|}{ Model B } \\
\hline$<25 \mathrm{~kg} / \mathrm{m}^{2}$ & Ref & & Ref & \\
\hline Overweight $^{\mathrm{b}}$ & $-2.5(-5.6$ to 0.8$)$ & 0.14 & $-4.6(-8.4$ to -0.7$)$ & 0.02 \\
\hline Obese $^{c}$ & $-5.5(-9.7$ to -1.1$)$ & 0.01 & $-4.2(-9.3$ to 1.3$)$ & 0.13 \\
\hline Overweight + Obese & $-3.4(-6.2$ to -0.5$)$ & 0.01 & $-4.5(-7.8$ to -1.0$)$ & 0.01 \\
\hline
\end{tabular}

Estimates are presented as a percentage change in average relative telomere length

Model A, adjustment for paternal and maternal age at birth, maternal education, newborn gender, gestational age, and birth weight. Model B, additionally adjusted for maternal smoking status, parity, newborn ethnicity, pregnancy complications, and cesarean section

${ }^{a} n=488$ for cord blood and $n=455$ for placenta

${ }^{\mathrm{b}} n=175$ for cord blood and $n=170$ for placenta

${ }^{c} n=80$ for cord blood and $n=77$ for placenta 
a

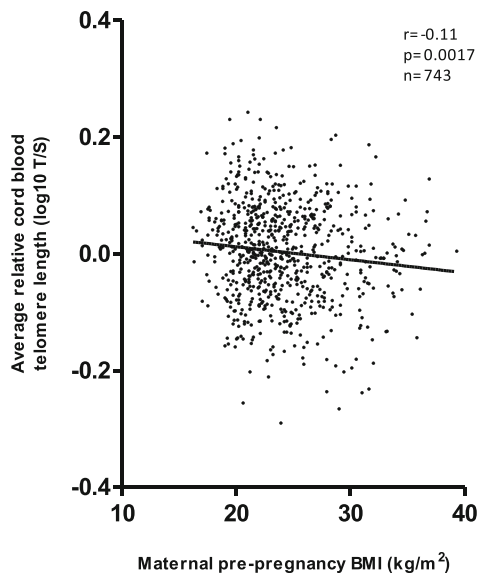

b

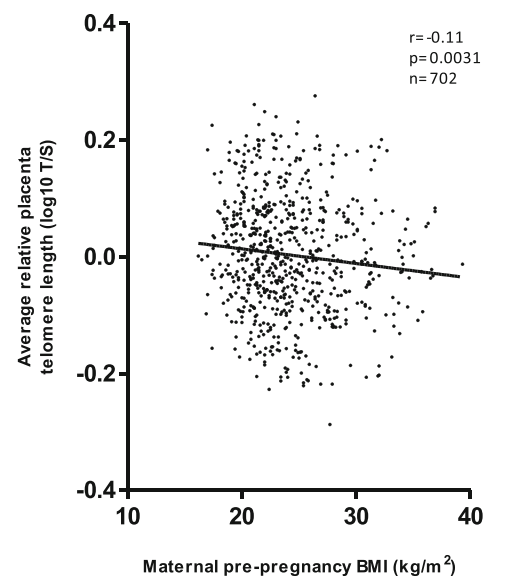

Fig. 1 Pearson correlation between maternal pre-pregnancy BMI and newborn telomere length. Relative average telomere lengths were expressed as the ratio of telomere copy number to single-copy gene number (T/S ratio). a Cord blood telomeres. b Placental telomeres

data from mean umbilical cord blood telomere lengths (measured using TRF), leading to an estimated value of approximately $10 \mathrm{~kb}[20,21,52,53]$, indicating a decrease of $0.50 \%$ leads to a loss of approximately $50 \mathrm{bp}$ in cord blood telomere length for each maternal BMI point increase. Based on longitudinal studies, an annual loss between 32.2 and $45.5 \mathrm{bp}$ is estimated in adult leukocytes [54], indicating that each maternal pre-pregnancy BMI point increase is equivalent to a loss of 1.1 to 1.6 telomeric year equivalence in adulthood (based on telomere attrition of 32.2-45.5 bp/year). This illustrates the public health significance of our findings, as newborns from obese mothers compared with newborns from normal weight mothers were biologically approximately 12 to 17 years older, based on telomeric year equivalence in adulthood.

Longitudinal studies have shown that telomere attrition is greatest during early life. Experimental studies in zebra finches show that telomere length in early life is predictive of longevity [55]. Therefore, our results of maternal BMI on newborn telomere length comprise an important public health finding.

Epidemiologic and animal studies indicate associations between pre-pregnancy maternal obesity and cardiovascular diseases and metabolic disorders in the offspring [45, 46]. Maternal obesity during the first trimester of pregnancy has been associated with a relative risk of childhood obesity of 2.3 (95\% CI, 2.0-2.6) at the age of 4 years [43]. A suggested mechanism that could underlie these relationships is in utero fetal programming by nutritional stimuli [38]. Fetuses have to adapt to the supply of nutrients crossing the placenta, which may permanently change their physiology and metabolism.

Our findings in newborns support the association between BMI and telomere length in adulthood. Metaanalytical evidence suggests that leukocyte telomere length is inversely associated with BMI in adulthood [33]. In adult women, Valdes et al. [56] reported on the average $240 \mathrm{bp}$ shorter telomeres in obese women $\mathrm{BMI}>30$ compared with lean women which corresponds to a age difference of 8.8 years. The role of the enzyme telomerase in the association between increased BMI and shortened telomeres is less well understood. Epel et al. [57] described low telomerase activity with increased BMI in 62 adult healthy women, which may be an important factor for the observed shortened telomeres in relation with body weight. Whether altered telomerase activity in mothers due to increased BMI also indicates altered neonatal telomerase activity remains unclear and might be an interesting topic of research. Obesity increases systemic inflammation and generation of reactive oxygen species (ROS) in fat cells [58-60]. These

Table 3 Pre-pregnancy maternal BMI and newborn telomere length

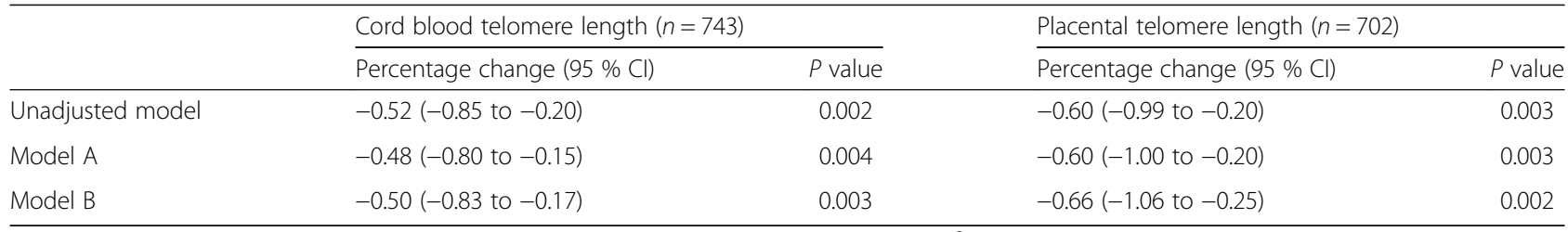

Estimates are presented as a percentage change in average relative telomere length for each $\mathrm{kg} / \mathrm{m}^{2} \mathrm{BMI}$ increase

Model A, adjustment for paternal and maternal age at birth, maternal education, newborn gender, gestational age, and birth weight

Model B, additionally adjusted for maternal smoking status, parity, newborn ethnicity, pregnancy complications, and cesarean section 
Table 4 Pre-pregnancy maternal BMI, weight gain during pregnancy, and newborn telomere length

\begin{tabular}{|c|c|c|c|c|}
\hline & \multicolumn{2}{|l|}{ Cord blood $(n=743)$} & \multicolumn{2}{|l|}{ Placenta $(n=702)$} \\
\hline & Percentage change (95 \% Cl) & $P$ value & Percentage change (95 \% Cl) & $P$ value \\
\hline \multicolumn{5}{|l|}{ Weight gain continuous } \\
\hline $\mathrm{BMI},+1 \mathrm{~kg} / \mathrm{m}^{2}$ & $-0.51(-0.85$ to -0.17$)$ & 0.003 & $-0.64(-1.06$ to -0.23$)$ & 0.002 \\
\hline Weight gain, $+5.6 \mathrm{~kg}$ & $-0.25(-1.69$ to 1.20$)$ & 0.73 & $0.20(-1.59$ to 2.02$)$ & 0.83 \\
\hline \multicolumn{5}{|l|}{ Weight gain categorical } \\
\hline $\mathrm{BMl},+1 \mathrm{~kg} / \mathrm{m}^{2}$ & $-0.51(-0.84$ to -0.17$)$ & 0.003 & $-0.68(-1.09$ to -0.27$)$ & 0.001 \\
\hline Sufficient & Ref & & Ref & \\
\hline Insufficient & $2.07(-1.77$ to 6.07$)$ & 0.29 & $3.01(-1.77$ to 8.03$)$ & 0.22 \\
\hline Excessive & $1.55(-1.58$ to 4.78$)$ & 0.33 & $2.39(-1.46$ to 6.38$)$ & 0.23 \\
\hline
\end{tabular}

Models adjusted according to model B (Table 2). Estimates are presented as a percentage change in average relative telomere length for each $\mathrm{kg} / \mathrm{m}^{2} \mathrm{BMI}$ increase or for a SD increase in weight gain during pregnancy. Categorical weight gain defined according to the Institute of Medicine guidelines [48]. Insufficient and excessive gestational weight gain in relation to maternal pre-pregnancy BMI (for underweight: total weight gain $<13$ and $>18$ kg; normal weight: total weight gain $<11.5$ and $>16.0 \mathrm{~kg}$; for overweight: total weight gain $<7.0$ and $>11.5 \mathrm{~kg}$; for obesity: total weight gain $<5.0$ and $>9.0 \mathrm{~kg}$, respectively)

high levels of ROS resulting in higher oxidative stress might explain accelerated shortening of telomeres in addition to cellular replication [61, 62]. As telomeres contain G-rich fragments that are highly sensitive to ROS, these higher levels of oxidative stress can lead to breakage of DNA and a more rapid decline in telomere length [63]. Higher maternal oxidative stress and inflammation status due to increased obesity might generate a higher inflammatory and oxidative stress intrauterine environment for the developing fetus, influencing telomere biology during the in utero life. Recent studies indeed showed that maternal obesity leads to increased oxidative stress in both mothers and newborns. Higher states of oxidative stress were observed in maternal plasma as well as in newborn plasma and placental tissue of obese mothers compared with normal weight mothers [64]. Increased levels of malondialdehyde, superoxide anion, and nitric oxide levels were observed in newborns of obese mothers [64, 65]. These higher levels of oxidative stress have been proposed to induce metabolic alterations that may act as mechanisms in fetal programming [66] and this may provide a link between maternal obesity and shortened telomere lengths in newborns.

In the ENVIRONAGE birth cohort, we observed (in unadjusted analysis), besides an association with pre-pregnancy
BMI, longer cord blood and placental telomeres in female newborns compared to male newborns, that telomeres tended to be longer with increased paternal age, and that cord blood telomeres were longer in association with higher maternal education, all of which are in accordance to recent studies [28, 29, 67]. A strength of our study is the large sample size of newborns with matching cord blood and placental tissue, to study telomere length associations. We found consistent results of shorter telomere length in both newborn cord blood and placenta in association with prepregnancy BMI. Further, our findings are generalizable as our study population is representative for the gestational segment of the population at large (Additional file 1: Table S1). Our associations remained unchanged after adjustments for different covariates and potential cofounders and persisted across subgroups or after excluding non-European newborns, mothers with pre-pregnancy BMI less than $18.5 \mathrm{~kg} / \mathrm{m}^{2}$, cesarean sections, and pregnancy complications, further suggesting an independent association. We need to address some limitations of this study. We do not have information on paternal BMI and recent epigenetic effects of paternal weight on newborns have been described [68, 69]. We used a real-time PCR method to determine telomere lengths, which has, in general, higher assay

Table 5 Sensitivity analyses

\begin{tabular}{|c|c|c|c|c|c|c|}
\hline & \multicolumn{3}{|c|}{ Cord blood telomere length } & \multicolumn{3}{|c|}{ Placental telomere length } \\
\hline & $n$ & Percentage change (95\% Cl) & $P$ value & $n$ & Percentage change (95\% Cl) & $P$ value \\
\hline Model B & 743 & $-0.50(-0.83$ to -0.17$)$ & 0.003 & 702 & $-0.66(-1.06$ to -0.25$)$ & 0.002 \\
\hline Excluding non-European & 658 & $-0.47(-0.82$ to -0.11$)$ & 0.01 & 621 & $-0.50(-0.93$ to -0.06$)$ & 0.03 \\
\hline Excluding $\mathrm{BMI}<18.5 \mathrm{~kg} / \mathrm{m}^{2}$ & 714 & $-0.43(-0.78$ to -0.07$)$ & 0.02 & 675 & $-0.61(-1.03$ to -0.17$)$ & 0.006 \\
\hline Excluding cesarean sections & 710 & $-0.50(-0.84$ to -0.16$)$ & 0.004 & 673 & $-0.59(-1.00$ to -0.18$)$ & 0.005 \\
\hline Excluding pregnancy complications & 665 & $-0.53(-0.89$ to -0.17$)$ & 0.004 & 628 & $-0.74(-1.19$ to -0.30$)$ & 0.001 \\
\hline Excluding all above & 542 & $-0.44(-0.87$ to -0.00$)$ & 0.05 & 513 & $-0.45(-0.98$ to 0.08$)$ & 0.09 \\
\hline
\end{tabular}

Estimates are presented as a percentage change in average relative telomere length for each $\mathrm{kg} / \mathrm{m}^{2} \mathrm{BMI}$ increase

All models were adjusted according to Model B (Table 2) 
variability compared to the traditionally used TRF method $[70,71]$. However, we participated in an inter-laboratory comparison and achieved coefficients of variation of less than $7 \%$. Further, we acknowledge the fact that variability within the placenta exists, and for our study the intraplacental variability for telomeres was $11 \%$. Recently, Factor-Litvak et al. [67] showed a strong correlation between newborn telomere length measured in cord blood and both age-adjusted paternal and maternal telomere lengths. As overweight mothers may potentially have shorter telomeres, the association between pre-pregnancy BMI and newborn telomere length might be mediated by maternal telomere lengths. This mediation could not be addressed in the ENVIRONAGE birth cohort at this moment as no data on maternal telomere lengths was available. Finally, we need to acknowledge that other potential important factors that occur during pregnancy, such as newborn telomerase activity and alteration of oxidative stress-related markers in mothers and newborns, and which might influence telomere length at birth, were not measured.

\section{Conclusions}

To our knowledge, this is the first study to report a strong association between maternal pre-pregnancy BMI and telomere lengths in newborns in a large birth cohort. Telomere length in early life predicts life span; therefore, our results on variation in offspring early-life telomere length in association with maternal BMI are a major step forward in unravelling the early life determinants of telomere length. Further, the public health impact is considerable, as in affluent societies approximately $30 \%$ of women of reproductive age are overweight. Our results add to the growing body of evidence that high maternal BMI impacts fetal programming. Maintaining a normal BMI during a women's reproductive age may promote molecular longevity in the offspring as exemplified by newborn telomere length. In this context, maternal overweight and obesity might be one of the most preventable environmental factors that may increase life expectations of newborns and may impact overall quality of life by decreasing comorbidities in adulthood.

\section{Additional file}

Additional file 1: Text S1. Telomere and single copy-gene reaction mixture and PCR cycling conditions. Table S1. Comparison characteristics of the ENVIRONAGE data with data of the birth register of Flanders (Northern part of Belgium). Figure S1. Flowchart of included mother newborn pairs. Figure S2. Pearson correlation between average relative telomere lengths in cord blood and placental tissue. (DOCX 237 kb)

\section{Abbreviations}

BMl: body mass index; Cl: confidence interval; CV: coefficient of variation; ENVIRONAGE: Environmental Influence on Ageing in Early Life; qPCR: quantitative real-time $P C R$; ROS: reactive oxygen species; SD: standard deviation; T/S ratio: telomere to single-copy gene ratio; TRF: terminal restriction fragment

\section{Funding}

The ENVIRONAGE birth cohort is supported by the EU Program "Ideas" (ERC-2012StG 310898) and by the Flemish Scientific Fund (FWO, G073315N).

Availability of data and materials

Data available on request.

\section{Authors' contributions}

TSN coordinates the ENVIRONAGE birth cohort and designed the current study together with DSM and MP. WG and DSM gave guidance to the midwives and performed quality control of the database. DSM performed the statistical analysis with guidance provided by TSN. DSM measured cord and placental telomere under supervision of MP and IDV. DSM and TSN wrote the first draft of the manuscript. All authors were involved in data interpretation and critical revision of the manuscript.

\section{Competing interests}

The authors declare that they have no competing interests.

\section{Consent for publication}

Not applicable.

\section{Ethics approval and consent to participate}

The study protocol was approved by the Ethical Committee of Hasselt University and East-Limburg Hospital in Genk (Belgium) and has been carried out according to the declaration of Helsinki. Written informed consent was obtained from all participating mothers.

\section{Author details}

${ }^{1}$ Centre for Environmental Sciences, Hasselt University, Hasselt 3500, Belgium. ${ }^{2} \mathrm{MRC} / \mathrm{PHE}$ Centre for Environment and Health, School of Public Health, Imperial College London, London W2 1PG, UK. ${ }^{3}$ Department of Obstetrics, East-Limburg Hospital, Genk 3600, Belgium. ${ }^{4}$ Channing Division of Network Medicine, Department of Medicine, Brigham and Women's Hospital and Harvard Medical School, Boston, MA 02215, USA. ${ }^{5}$ Program in Genetic Epidemiology and Statistical Genetics, Harvard School of Public Health, Boston, MA 02115, USA. ${ }^{6}$ Department of Public Health \& Primary Care, Leuven University, Leuven 3000, Belgium.

Received: 24 June 2016 Accepted: 8 September 2016

Published online: 18 October 2016

References

1. Fleten C, Nystad W, Stigum H, Skjaerven R, Lawlor DA, Davey Smith G, Naess O. Parent-offspring body mass index associations in the Norwegian Mother and Child Cohort Study: a family-based approach to studying the role of the intrauterine environment in childhood adiposity. Am J Epidemiol. 2012;176(2):83-92.

2. O'Brien TE, Ray JG, Chan WS. Maternal body mass index and the risk of preeclampsia: a systematic overview. Epidemiology. 2003;14(3):368-74.

3. Torloni MR, Betran AP, Horta BL, Nakamura MU, Atallah AN, Moron AF, Valente O. Prepregnancy BMl and the risk of gestational diabetes: a systematic review of the literature with meta-analysis. Obes Rev. 2009;10(2):194-203.

4. Rahman MM, Abe SK, Kanda M, Narita S, Rahman MS, Bilano V, Ota E, Gilmour S, Shibuya K. Maternal body mass index and risk of birth and maternal health outcomes in low- and middle-income countries: a systematic review and meta-analysis. Obes Rev. 2015;16(9):758-70.

5. Ehrenberg HM, Durnwald CP, Catalano P, Mercer BM. The influence of obesity and diabetes on the risk of cesarean delivery. Am J Obstet Gynecol. 2004; 191(3):969-74.

6. Blackburn EH. Structure and function of telomeres. Nature. 1991;350(6319): 569-73.

7. Brouilette SW, Moore JS, McMahon AD, Thompson JR, Ford I, Shepherd J, Packard CJ, Samani NJ, West of Scotland Coronary Prevention Study Group. Telomere length, risk of coronary heart disease, and statin treatment in the West of Scotland Primary Prevention Study: a nested case-control study. Lancet. 2007;369(9556):107-14.

8. Haycock PC, Heydon EE, Kaptoge S, Butterworth AS, Thompson A, Willeit P. Leucocyte telomere length and risk of cardiovascular disease: systematic review and meta-analysis. BMJ. 2014;349:g4227. 
9. Willeit P, Raschenberger J, Heydon EE, Tsimikas S, Haun M, Mayr A, Weger S, Witztum JL, Butterworth AS, Willeit J, et al. Leucocyte telomere length and risk of type 2 diabetes mellitus: new prospective cohort study and literature-based meta-analysis. PLoS One. 2014;9(11):e112483.

10. Chen S, Lin J, Matsuguchi T, Blackburn E, Yeh F, Best LG, Devereux RB, Lee ET, Howard BV, Roman MJ, et al. Short leukocyte telomere length predicts incidence and progression of carotid atherosclerosis in American Indians: the Strong Heart Family Study. Aging (Albany NY). 2014;6(5):414-27.

11. Hunt SC, Kimura M, Hopkins PN, Carr JJ, Heiss G, Province MA, Aviv A. Leukocyte telomere length and coronary artery calcium. Am J Cardiol. 2015;116(2):214-8.

12. Cawthon RM, Smith KR, O'Brien E, Sivatchenko A, Kerber RA. Association between telomere length in blood and mortality in people aged 60 years or older. Lancet. 2003;361(9355):393-5.

13. Fitzpatrick AL, Kronmal RA, Kimura M, Gardner JP, Psaty BM, Jenny NS, Tracy $\mathrm{RP}$, Hardikar S, Aviv A. Leukocyte telomere length and mortality in the Cardiovascular Health Study. J Gerontol A Biol Sci Med Sci. 2011;66(4):421-9.

14. Needham BL, Rehkopf D, Adler N, Gregorich S, Lin J, Blackburn EH, Epel ES. Leukocyte telomere length and mortality in the National Health and Nutrition Examination Survey, 1999-2002. Epidemiology. 2015;26(4):528-35.

15. Hjelmborg JB, Dalgard C, Moller S, Steenstrup T, Kimura M, Christensen K, Kyvik KO, Aviv A. The heritability of leucocyte telomere length dynamics. J Med Genet. 2015;52(5):297-302.

16. Honig LS, Kang MS, Cheng R, Eckfeldt JH, Thyagarajan B, Leiendecker-Foster C, Province MA, Sanders JL, Perls T, Christensen K, et al. Heritability of telomere length in a study of long-lived families. Neurobiol Aging. 2015;36(10):2785-90

17. Slagboom PE, Droog S, Boomsma DI. Genetic determination of telomere size in humans: a twin study of three age groups. Am J Hum Genet. 1994; 55(5):876-82.

18. Martens DS, Nawrot TS. Air pollution stress and the aging phenotype: the telomere connection. Curr Environ Health Rep. 2016;3(3):258-69.

19. Pieters $N$, Janssen BG, Dewitte $H$, Cox B, Cuypers A, Lefebvre W, Smeets $K$, Vanpoucke C, Plusquin M, Nawrot TS. Biomolecular markers within the core axis of aging and particulate air pollution exposure in the elderly: a crosssectional study. Environ Health Perspect. 2016;124(7):943-50.

20. Okuda K, Bardeguez A, Gardner JP, Rodriguez P, Ganesh V, Kimura M, Skurnick J, Awad G, Aviv A. Telomere length in the newborn. Pediatr Res. 2002;52(3):377-81.

21. Youngren K, Jeanclos E, Aviv H, Kimura M, Stock J, Hanna M, Skurnick J, Bardeguez A, Aviv A. Synchrony in telomere length of the human fetus. Hum Genet. 1998;102(6):640-3.

22. Frenck Jr RW, Blackburn EH, Shannon KM. The rate of telomere sequence loss in human leukocytes varies with age. Proc Natl Acad Sci U S A. 1998; 95(10):5607-10.

23. Barrett $\mathrm{JH}$, lles MM, Dunning AM, Pooley KA. Telomere length and common disease: study design and analytical challenges. Hum Genet. 2015;134(7):679-89.

24. Shalev I, Entringer S, Wadhwa PD, Wolkowitz OM, Puterman E, Lin J, Epel ES. Stress and telomere biology: a lifespan perspective. Psychoneuroendocrinology. 2013;38(9):1835-42.

25. Entringer S, Epel ES, Lin J, Buss C, Shahbaba B, Blackburn EH, Simhan HN, Wadhwa PD. Maternal psychosocial stress during pregnancy is associated with newborn leukocyte telomere length. Am J Obstet Gynecol. 2013; 208(2):134 e1-7.

26. Marchetto NM, Glynn RA, Ferry ML, Ostojic M, Wolff SM, Yao R, Haussmann MF. Prenatal stress and newborn telomere length. Am J Obstet Gynecol. 2016:215(1):94 e1-8.

27. Salihu HM, Pradhan A, King L, Paothong A, Nwoga C, Marty PJ, Whiteman V. Impact of intrauterine tobacco exposure on fetal telomere length. Am J Obstet Gynecol. 2015;212(2):205.e1-8.

28. Wojcicki JM, Olveda R, Heyman MB, Elwan D, Lin J, Blackburn E, Epel E. Cord blood telomere length in Latino infants: relation with maternal education and infant sex. J Perinatol. 2016:36:235-41.

29. Entringer S, Epel ES, Lin J, Blackburn EH, Buss C, Shahbaba B, Gillen DL, Venkataramanan R, Simhan HN, Wadhwa PD. Maternal folate concentration in early pregnancy and newborn telomere length. Ann Nutr Metab. 2015;66(4):202-8.

30. Biron-Shental T, Sukenik-Halevy R, Sharon Y, Goldberg-Bittman L, Kidron D, Fejgin MD, Amiel A. Short telomeres may play a role in placental dysfunction in preeclampsia and intrauterine growth restriction. Am J Obstet Gynecol. 2010;202(4):381.e1-7.

31. Davy $P$, Nagata M, Bullard P, Fogelson NS, Allsopp R. Fetal growth restriction is associated with accelerated telomere shortening and increased expression of cell senescence markers in the placenta. Placenta. 2009;30(6):539-42.
32. Biron-Shental T, Sukenik-Halevy R, Naboani H, Liberman M, Kats R, Amiel A. Telomeres are shorter in placentas from pregnancies with uncontrolled diabetes. Placenta. 2015;36(2):199-203.

33. Muezzinler A, Zaineddin AK, Brenner H. Body mass index and leukocyte telomere length in adults: a systematic review and meta-analysis. Obes Rev. 2014;15(3):192-201.

34. Painter RC, de Rooij SR, Bossuyt PM, Simmers TA, Osmond C, Barker DJ, Bleker $\mathrm{OP}$, Roseboom TJ. Early onset of coronary artery disease after prenatal exposure to the Dutch famine. Am J Clin Nutr. 2006;84(2):322-7. quiz 466-7.

35. Huang C, Li Z, Wang M, Martorell R. Early life exposure to the 1959-1961 Chinese famine has long-term health consequences. J Nutr. 2010;140(10):1874-8.

36. Ravelli GP, Stein ZA, Susser MW. Obesity in young men after famine exposure in utero and early infancy. N Engl J Med. 1976;295(7):349-53.

37. Roseboom TJ, van der Meulen JH, Ravelli AC, van Montfrans GA, Osmond C, Barker DJ, Bleker OP. Blood pressure in adults after prenatal exposure to famine. J Hypertens. 1999;17(3):325-30.

38. Leddy MA, Power ML, Schulkin J. The impact of maternal obesity on maternal and fetal health. Rev Obstet Gynecol. 2008;1(4):170-8.

39. Ehrenberg HM, Mercer BM, Catalano PM. The influence of obesity and diabetes on the prevalence of macrosomia. Am J Obstet Gynecol. 2004;191(3):964-8.

40. Rasmussen SA, Chu SY, Kim SY, Schmid CH, Lau J. Maternal obesity and risk of neural tube defects: a metaanalysis. Am J Obstet Gynecol. 2008;198(6):611-9.

41. Watkins ML, Rasmussen SA, Honein MA, Botto LD, Moore CA. Maternal obesity and risk for birth defects. Pediatrics. 2003;111(5 Pt 2):1152-8.

42. Aune D, Saugstad OD, Henriksen T, Tonstad S. Maternal body mass index and the risk of fetal death, stillbirth, and infant death: a systematic review and meta-analysis. JAMA. 2014;311(15):1536-46.

43. Whitaker RC. Predicting preschooler obesity at birth: the role of maternal obesity in early pregnancy. Pediatrics. 2004;114(1):e29-36.

44. Forno E, Young OM, Kumar R, Simhan H, Celedon JC. Maternal obesity in pregnancy, gestational weight gain, and risk of childhood asthma. Pediatrics. 2014;134(2):e535-46.

45. Gaillard R. Maternal obesity during pregnancy and cardiovascular development and disease in the offspring. Eur J Epidemiol. 2015;30(11):1141-52.

46. Tan HC, Roberts J, Catov J, Krishnamurthy R, Shypailo R, Bacha F. Mother's pre-pregnancy BMI is an important determinant of adverse cardiometabolic risk in childhood. Pediatr Diabetes. 2015;16(6):419-26.

47. Barker DJ. The origins of the developmental origins theory. J Intern Med. 2007;261(5):412-7

48. Rasmussen KM, Yaktine AL, editors. Weight Gain During Pregnancy: Reexamining the Guidelines. Washington, DC: National Academies Press; 2009.

49. Cox B, Martens E, Nemery B, Vangronsveld J, Nawrot TS. Impact of a stepwise introduction of smoke-free legislation on the rate of preterm births: analysis of routinely collected birth data. BMJ. 2013;346:f441.

50. Janssen BG, Munters E, Pieters N, Smeets K, Cox B, Cuypers A, Fierens F, Penders J, Vangronsveld J, Gyselaers W, et al. Placental mitochondrial DNA content and particulate air pollution during in utero life. Environ Health Perspect. 2012;120(9):1346-52.

51. Cawthon RM. Telomere length measurement by a novel monochrome multiplex quantitative PCR method. Nucleic Acids Res. 2009;37(3):e21.

52. Akkad A, Hastings R, Konje JC, Bell SC, Thurston H, Williams B. Telomere length in small-for-gestational-age babies. BJOG. 2006;113(3):318-23.

53. Allsopp R, Shimoda J, Easa D, Ward K. Long telomeres in the mature human placenta. Placenta. 2007;28(4):324-7.

54. Muezzinler A, Zaineddin AK, Brenner H. A systematic review of leukocyte telomere length and age in adults. Ageing Res Rev. 2013; 12(2):509-19.

55. Heidinger BJ, Blount JD, Boner W, Griffiths K, Metcalfe NB, Monaghan P. Telomere length in early life predicts lifespan. Proc Natl Acad Sci U S A. 2012;109(5):1743-8.

56. Valdes AM, Andrew T, Gardner JP, Kimura M, Oelsner E, Cherkas LF, Aviv A, Spector TD. Obesity, cigarette smoking, and telomere length in women Lancet. 2005;366(9486):662-4.

57. Epel ES, Lin J, Wilhelm FH, Wolkowitz OM, Cawthon R, Adler NE, Dolbier C, Mendes WB, Blackburn EH. Cell aging in relation to stress arousal and cardiovascular disease risk factors. Psychoneuroendocrinology. 2006;31(3):277-87.

58. Ahima RS. Connecting obesity, aging and diabetes. Nat Med. 2009;15(9):996-7.

59. Furukawa S, Fujita T, Shimabukuro M, Iwaki M, Yamada $Y$, Nakajima $Y$, Nakayama O, Makishima M, Matsuda M, Shimomura I. Increased oxidative stress in obesity and its impact on metabolic syndrome. J Clin Invest. 2004; 114(12):1752-61. 
60. Minamino T, Orimo M, Shimizu I, Kunieda T, Yokoyama M, Ito T, Nojima A, Nabetani A, Oike Y, Matsubara $\mathrm{H}$, et al. A crucial role for adipose tissue p53 in the regulation of insulin resistance. Nat Med. 2009;15(9):1082-7.

61. von Zglinicki T. Oxidative stress shortens telomeres. Trends Biochem Sci. 2002;27(7):339-44

62. Saretzki G, Von Zglinicki T. Replicative aging, telomeres, and oxidative stress. Ann N Y Acad Sci. 2002;959:24-9.

63. Kawanishi S, Oikawa S. Mechanism of telomere shortening by oxidative stress. Ann N Y Acad Sci. 2004;1019:278-84.

64. Malti N, Merzouk H, Merzouk SA, Loukidi B, Karaouzene N, Malti A, Narce M. Oxidative stress and maternal obesity: feto-placental unit interaction. Placenta. 2014;35(6):411-6.

65. Gallardo JM, Gomez-Lopez J, Medina-Bravo P, Juarez-Sanchez F, ContrerasRamos A, Galicia-Esquivel M, Sanchez-Urbina R, Klunder-Klunder M. Maternal obesity increases oxidative stress in the newborn. Obesity (Silver Spring). 2015;23(8):1650-4.

66. Myatt L. Placental adaptive responses and fetal programming. J Physiol. 2006;572(Pt 1):25-30

67. Factor-Litvak P, Susser E, Kezios K, McKeaque I, Kark JD, Hoffman M, Kimura M Wapner R, Aviv A. Leukocyte telomere length in newborns: implications for the role of telomeres in human disease. Pediatrics. 2016;137(4):e20153927.

68. Soubry A, Murphy SK, Wang F, Huang Z, Vidal AC, Fuemmeler BF, Kurtzberg J, Murtha A, Jirtle RL, Schildkraut JM, et al. Newborns of obese parents have altered DNA methylation patterns at imprinted genes. Int J Obes (Lond). 2015;39(4):650-7.

69. Soubry A, Schildkraut JM, Murtha A, Wang F, Huang Z, Bernal A, Kurtzberg J, Jirtle RL, Murphy SK, Hoyo C. Paternal obesity is associated with IGF2 hypomethylation in newborns: results from a Newborn Epigenetics Study (NEST) cohort. BMC Med. 2013;11:29.

70. Aviv A, Hunt SC, Lin J, Cao X, Kimura M, Blackburn E. Impartial comparative analysis of measurement of leukocyte telomere length/DNA content by Southern blots and qPCR. Nucleic Acids Res. 2011;39(20):e134.

71. Kimura M, Stone RC, Hunt SC, Skurnick J, Lu X, Cao X, Harley CB, Aviv A Measurement of telomere length by the Southern blot analysis of terminal restriction fragment lengths. Nat Protoc. 2010;5(9):1596-607.

\section{Submit your next manuscript to BioMed Central and we will help you at every step:}

- We accept pre-submission inquiries

- Our selector tool helps you to find the most relevant journal

- We provide round the clock customer support

- Convenient online submission

- Thorough peer review

- Inclusion in PubMed and all major indexing services

- Maximum visibility for your research

Submit your manuscript at www.biomedcentral.com/submit 